\title{
Water Availability Challenges in Low-Income Areas of Agbowo Community, Ibadan, Nigeria
}

Tosin Kolajo Gbadegesin, Centre for Sustainable Development, University of Ibadan, Nigeria

Olawale Olayide, Centre for Sustainable Development, University of Ibadan, Nigeria

\begin{abstract}
Water is crucial to life. This has led to the inclusion of a specific water-related target in the Millennium Development Goals (MDGs) and Sustainable Development Goals (SDGs). The study by World Health Organization (WHO) stated that about 663 million people worldwide have no adequate access to safe drinking water while UNICEF stated that about 65 million Nigerians have no access to safe water supplies. It is against this background that this study was conducted in Agbowo Community. The community has a high rate of economic poverty and poor living conditions. The study determined the gap between water supply and demand and enumerated physical and socio-economic variables that influence water availability. The study noted that a significant number of respondents expressed optimism despite the seriousness of the challenges and recommended massive remediation of the area as most of the water sources are contaminated by sewage.
\end{abstract}

\section{KEYWORDS}

Access to Water, Low-Income Areas, MDGs, Remediation, SDGs, Water Supply and Demand

\section{INTRODUCTION}

As the earth warms, the combination of shrinking glaciers, reduced snowpack and erratic rainfall raises fears of water shortages, particularly in the world's most vulnerable regions. Water is essential for many aspects of human development like health, food and nutrition and well-being. This led to the inclusion of a specific water-related target in the Millennium Development Goals (MDGs) and Sustainable Development Goals (SDGs). The Millennium Development Goals (MDGs) set a target to reduce by half the number of people living without sustainable access to safe drinking water and basic sanitation. The MDGs' target was a part of the International Decade for Action, Water for Life for the period of 2005 to 2015 (Ludi 2009). The Sustainable Development Goals (SDGs) also set the target to achieve universal and equitable access to safe and affordable drinking water for all by 2030 (SDSN 2015). This shows that the supply of safe water still remains unsatisfactory, although the importance of water is not only related to drinking as it also plays a crucial role in washing, bathing, cooking and other domestic activities. In fact, about 6 to 8 million people die annually from the consequences of disasters and water-related illnesses, inadequate sanitation and poor hygiene practices (Majuru et al. 2011).

\section{DOI: 10.4018/IJCEWM.20210101.oa2}

This article published as an Open Access article distributed under the terms of the Creative Commons Attribution License (http://creativecommons.org/licenses/by/4.0/) which permits unrestricted use, distribution, and production in any medium, provided the author of the original work and original publication source are properly credited. 
Globally, access to safe and adequate water resources remains one of the major challenges in developing countries nowadays. Poor provision of safe and adequate water resources has the potential to trigger a global food crisis of the 21 st century. This has to do with the fact that everyone has a right to access potable water (United Nations 2010) and that water is one of the most important public goods. Water constitutes over $70 \%$ of the human body and is considered as the most vital component of life after oxygen (Doe 2007). Report by UNESCO (2013) highlighted that about 783 million people globally lack access to clean water supply while about 2 billion individuals do not have access to adequate sanitation.

Water is central to life. It is part of the five basic human needs: air, water, food, light, and heat. Water is a common factor to the other four. It is therefore not an understatement to say water is life, because it forms an appreciable proportion of all living things including man. Water constitutes about $80 \%$ of animal cells. The human body by weight consists of about $70 \%$ water and several body functions depend on water (UNDP Human development report, 2006). In the General Assembly of the human right to water and sanitation, the Assembly established the right of every human being to have access to sufficient water for personal and domestic uses (between 50 and 100 litres of water per person per day), which must be safe, acceptable and affordable (water costs should not exceed $3 \%$ of household income), and physically accessible i.e. the water source has to be within 1,000 metres of the home and collection time should not exceed 30 minutes (Hope, 2006).

Elimelech (2006) and UNICEF/WHO (2013) stated that over 1 billion people lack access to potable water and all of them live in low-income countries. WHO (2015) found out that about 663 million people worldwide have no access to adequate drinking water supplies. Kelay et al. (2006) and Segrave (2007) stated that urban areas all over the world are currently experiencing a range of dynamic global and regional pressures. These cities are facing difficulty in managing scarce water resources as well as in delivering water supply and sanitation services.

At present, about 30 countries are considered to be water-stressed; of these, 20 are experiencing a prolonged drought. It is envisaged that by the year 2020, the proportion of water-scarce countries will likely approach 35 . Water shortages in Pakistan and India, for example, threaten the viability of agriculture in the region. By 2030, the overall demand for water may outstrip supply by $40 \%$. And by the 2090s, without significant reductions in GHGs emissions, the proportion of the global land surface in extreme drought could increase from 3\% today to 30\% (Christoph et al. 2011; Intergovernmental Panel Climate Change, 2014). It has also been estimated that one-third of the population of the developing world will face severe water shortages by 2025, while about 10 African countries are expected to be water-stressed by 2025 (Bradley et al. 2007).

UNICEF (2015) stated that about half of the people living in areas with poor water sources are in Sub-Saharan Africa and also projected that two-thirds of Africa's population will be affected by water scarcity by 2050. Extreme drought has affected countries like Somalia, Kenya, and other East African countries. They have experienced below-average rainfall since the late 1990s, contributing to a 30\% reduction in crop yields and famines in 2010, 2011, and 2016 (John 2016). Also, about 65 million Nigerians have no access to safe and adequate water supplies; a number rose dramatically to 90 million in 2015 (UNICEF 2015). Nigeria did not achieve the MDG target of halving by 2015 the population without adequate access to potable drinking water sources. She ranks behind many other Sub-Saharan African countries such as Ghana, Rwanda, Botswana, and Sierra Leone in access to potable water (Stone 2009).

Interventions aimed at improving access to water in low-income areas can be discussed within the context of improving living conditions, tackling poverty and contributing to economic growth. United Nations compared water consumption to its availability and predicted that by the middle of this century; about 2 billion to 7 billion individuals will be faced with water security issues. Owing to this emerging reality, water has been described as "the oil of the twenty-first century", a scarce commodity that will be a source of conflict between peoples and nations (Obeta 2016). 
The process of urbanization holds great promise for economic and social progress of a nation. On the other hand, this process is confronted with a lot of challenges. One such challenge is the increasing vulnerability to quality water supply among households. Low-income urban households lack access to potable water and therefore have to supplement their limited supply with water from sources such as streams/rivers and wells. Indeed, whereas the water is available, the quantity is decreasing, and the quality is also compromised mainly due to high population growth, climate change as well as low investments by the state (WASH, 2012).

Given that most of the urban population growth is occurring in communities that are poor and settlements that are informal and unplanned, the task of reaching the unserved has continued to become increasingly difficult. These informal settlements are often known as slums, low-income areas, squatter settlements etc. now house between $40 \%$ and $70 \%$ of the urban population and range from high density, squalid inner-city tenements to spontaneous, peri-urban settlements lacking legal recognition. Some are more than fifty years old and others are the result of recent urban expansion (Majuru et al., 2011). Similarly, due to neglect and poor infrastructural facilities, most of the periurban areas have ended up as slums and Nigeria has the highest slum population of about $79.2 \%$ in urban areas in the world. This poses a serious threat to the overall social-economic development of the country considering the high population of Nigerians residing in these neglected areas. Focusing attention on peri-urban areas in terms of overall development has become more imperative if Nigeria's development aspirations are to be fully achieved (Nwankwoala, 2011).

Water Aid (2008) noted that inadequate access to improved Water supply, Sanitation and Hygiene (WASH) facilities is one of the recurring problems of low-income urban areas. While access to improved water supply and sanitation are known for urban and rural areas courtesy of several studies conducted in the country, very little is known about the situation in low-income urban areas which makes it extremely difficult to plan for appropriate interventions. The WASH situations for peri-urban areas are most likely to be worse than the urban areas. According to United Nations Global Issues (2012), addressing the rights of people to safe water sources and adequate sanitation in low-income urban areas is very difficult due to inadequate information for effective programme planning and implementation, hence the need for this study.

\section{Objectives of the Study}

The general aim of the study was to examine the causes of water shortages in a low-income urban area of Agbowo community. Specific objectives of the study were to:

1. Enumerate the status of water availability in Agbowo community;

2. Investigate survival strategies during scarcity and quality of available water;

3. Profile environmental challenges contributing to contamination of water sources and look at intervention efforts aimed at improving access to water in the area;

4. Estimate the quantity of water needed against quantity obtainable.

\section{Significance of the Study}

The threat to water resources has brought into focus the urgent need for planned action to manage water resources effectively as it is widely acknowledged that water is a major limiting factor in socioeconomic development. The United Nations (UN) in her declaration draws attention to the importance of water and water-related activities in supporting the development and eradicating poverty (WWAP, 2019). Regardless of location and legal status, low-income settlements have several characteristics in common. Their residents often lack access to adequate and affordable basic water supply and sanitation services, lack adequate housing and have limited or no access to other infrastructure and services such as solid waste, stormwater drainage, street lighting, roads and footpaths. Improving 
services in these areas is a practical challenge because of their haphazard layout, high density and/or difficult geographical and environmental conditions (The Sphere Project, 2011).

There is, therefore, a need for effective study on water supply challenges in low-income urban areas. In this regard, Agbowo community have characteristics of such an area. The study provides an exciting opportunity to advance understanding of the challenges faced in this area by taking an empirical approach to the problem. The findings will contribute to the ongoing debate among policy implementation scholars on the best approach to address water availability challenges.

\section{Organization of the Paper}

This report is organized into five sections. The first section comprises of introduction to the study, objectives, significance of the research, and report organization. The second section is made up of a review of empirical studies and the study hypothesis. The third section narrates methodologies used in this study, in line with the description of the study area. The fourth section deals with the results and discussions of the findings, while conclusion, future research work and limitation are presented in the fifth section.

\section{LITERATURE REVIEW AND HYPOTHESIS}

\section{Theoretical Framework}

The study is based on the theoretical framework of Sustainable Livelihood (Figure 1) which was first developed by the Department for International Development (DFID, 2001). The framework has been used extensively to provide analytical contexts for the formulation of sustainable and propoor development policies especially in developing economies. The Department for International Development (DfID), UN system including the Food and Agriculture Organization (FAO), United

Figure 1. The adapted sustainable livelihood framework (Source: Murray \& Ferguson, 2007)




Nations Development Program (UNDP) and national governments have actively used the SLF since the 1990s. The major achievements of the framework are its contribution to engendering a significant shift in development thinking towards a greater focus on poverty reduction through direct investment in improving household welfare. This paradigm has helped prioritized people as the focal subjects of any policy planning and design, thus creating better scope for large scale poverty reduction strategies (Clarke and Darney, 2008; Olayide \& Ikpi, 2013).

The Sustainable Livelihoods framework uses three broad dimensions of capital, vulnerability context and stages of transition to understand the experiences of individuals living in poverty. Asset highlights individuals' existing valuable capabilities in pursuing a sustainable livelihood. Vulnerability context aims to understand the external factors that influence an individual' assets and the opportunities that are open to them. While individuals can and do make choices that make them more vulnerable to poverty, understanding how broader, systemic forces impact individual choice or lack of choice is critical to developing practical and strategic supports and programs. The framework identified systems, cycles, trends, and shocks as four key forces that can make an individual vulnerable to poverty. A stage of Transition identifies key patterns of progress towards a sustainable livelihood. These include surviving, getting by, making changes, getting ahead, and Thriving. As individuals build their assets, they increase their resilience and ability to thrive (Murray \& Ferguson, 2007).

\section{Hypothesis}

The hypothesis of this study emanates from the theoretical framework of Sustainable Livelihood framework, first developed by the Department for International Development (DFID, 2001) and used to provide analytical contexts for the formulation of pro-poor development policies in developing economies.

Null Hypothesis $\left(\mathbf{H}_{\mathbf{0}}\right)$ : There is no significant relationship between household water demand per day and quantity available.

\section{Review of Empirical Studies}

A number of studies have looked at water supply challenges. For example, Trocaire (2015) stated there is a dwindling supply of safe drinking water caused by an increase in global temperatures as a consequence of climate change, a major problem impacting the nations in many dimensions. Olayide et al. (2016) stated that drought and flood are consequences of climate change and this makes people vulnerable to inundation, pollution, and contamination of taps and valves. Doe (2007); Murinda (2011); Hove and Tirimboi (2011) emphasized the availability of water as one of the critical challenges among urban communities. Chipeta (2009) investigated the daily water consumption per capita of some inhabitants in the city of Blantyre and found it to be far below the standard of 15 Litres per person per day as recommended in the sphere standards handbook (The Sphere Project, 2011). Van Vuuren (2009) looked at the current water situations and made some recommendations on what the business community and industry can collectively do to alleviate the problem of water shortage.

UN Water (2019), stated that the progress made since 2000 in delivering clean water to 1.5 billion people around the world is now under threat as one in nine people do not have access to clean water close to home, and just under two-thirds of the world's population live in areas of physical water scarcity where demand for water exceeds supply. WWAP (2015) stated that, globally, water usage has been increasing by one per cent annually since the 1980s due to the increased use in developing countries. The trend is expected to last until 2050 and is expected to be intensified by climate change. Findings by UN Water (2019) reveal that only one in three countries with less than $99 \%$ of basic water coverage is on track to achieve the required universal water coverage stipulated by Sustainable Development Goal 6 by 2030. It reported that the failure to provide safe drinking water and adequate sanitation services to all people is, perhaps, the greatest development failure of the 29th century. 
Van Vuuren (2009) mentioned issues around the water problems such as poor quality, water scarcity, and dysfunctional municipal water infrastructures that have resulted in the potential water crisis widely publicized in the media in South Africa. Ward (2007) estimated that by 2050 some $40 \%$ of the world population could be experiencing water shortages. Sigenu (2006) outlined that South Africa is one of the countries likely to join water shortage ranks by 2025 .

Adah and Abok (2013) noted that although Nigeria is blessed with abundant water resources (estimated at 226 billion cubic meters of surface water and about 40 billion cubic meters of groundwater), her rural populations are largely deprived of and lack access to adequate water supplies. Ezenwanji (2012) went on to state that a significant proportion of the Nigerian rural population continue to use rivers, ponds, lakes and harvested rain as their main sources of water supply and blamed limited access to water supplies by a significant proportion of the Nigerian rural population on institutional, socio-economic and environmental factors.

Toyobo and Tanimowo (2011) attributed the prevailing water poverty in many rural communities of Nigeria to climate change, poor sustainability of water infrastructure, the paucity of funds, inadequate technology and lack of political will. Nyaba (2009) attributed the poor service delivery in the Nigerian water sector to rent-seeking and poor governance of safe drinking water to a large segment of the Nigerian rural population and the inefficient system management which does not take into cognizance the sustainability of the supply system for future generations. Olaleye (2010) and Akpomunie (2010) noted that the provision of adequate, clean, reliable and potable water in Nigerian rural areas remains a challenge which needs to be tackled considering the fact that a larger percentage of the population live in rural areas.

Africa Development Bank Group (2013) reported over 300 million people in Africa do not have reasonable access to safe drinking water and adequate sanitation, giving it the lowest water supply coverage of any region in the world. This access is much worse in the rural areas where only about $47 \%$ is coverage, compared with $85 \%$ coverage in the urban areas. According to the Emergency Events Database [EM-DAT] (2013), 70\% of major global droughts occurred in Africa in 2012. Kenya, Somalia, Sudan, Malawi, Angola, Chad and Ethiopia were particularly hit hard, and more than 16 million people in those countries were affected. In the same year, floods claimed 363 lives in Nigeria (Ajijah 2013) and 65 lives in Niger (BBC News 2012). In 2013, heavy rains continued with major flooding in Sudan, South Sudan, Mali, South Africa, Zimbabwe, Botswana and Mozambique (Emergency Events Database [EM-DAT], 2013).

From the foregoing, it is clear that numerous studies have considered water supply challenges from different perspectives. However, these studies focused on rural and urban areas, and are yet to provide holistic analyses on water availability challenges in low-income urban areas. It is against this background the study was conducted in Agbowo Community, Ibadan, Nigeria from June to October 2018.

\section{METHODOLOGY}

\section{Study Area}

The study was carried in Agbowo Community; it is a low-income urban community in Ibadan North Local Government Area of Oyo State, Nigeria. The community is located on latitude $7^{\circ} 26^{\prime} 39^{\prime \prime}$ N and longitude $3^{\circ} 54^{\prime} 57^{\prime}$ ' E. It is one of the largest communities in Ibadan North. The community is a low-income urban area with high rate of economic poverty and poor living conditions, limited access to adequate and affordable safe water supply and basic sanitation services, inadequate housing plan, haphazard layout, and/or difficult geographical and environmental conditions, prevailing high population densities etc. 


\section{Sampling Methods, Data Sources and Collection Methods}

Both qualitative and quantitative data were collected. Quantitative data was collected using KOBO collect software - an android-based application for collecting data. For convenience, 127 households were randomly selected on the basis of the severity of water supply challenges. In the second stage, 2 individuals who are 18 years and above were randomly picked from each household and used to collect information on the main source of water, the time it takes to collect water, methods used for treatment etc. A total of two hundred and fifty-four (254) individuals were altogether sampled for data collection. Also, purposive sampling of influential people in the community such as business persons, religious leaders and traditional leaders was used to identify key informants. The study selected $10 \%$ of the respondents from the Sango area to test the validity and reliability of the survey instrument.

\section{Data Analysis}

Statistical computations were carried out using Statistical Package for Social Science (SPSS) software. Data obtained were entered and analysed descriptively using frequencies, tables, graphs and simple percentages. Mean, median, mode and standard deviation were calculated for continuous variables and Chi-square was used to test for associations between categorical variables and proportions. A confidence level of $99 \%$ was used and p-values $£ 0.01$ considered statistically significant.

\section{RESULT AND DISCUSSION}

\section{Socio-Demographic Distribution of Respondents}

Respondents were $48 \%$ male and 52\% female in total (Table 1). Majority of the respondents (48\%) possesses secondary education.

The average age of respondents was $33 \pm 10$ years (Table 2). Their average monthly income was $\$ 66 \pm \$ 33$ and the average number of occupants per household was observed to be $16 \pm 5$.

\section{Status of Water Availability in Agbowo Community}

The study showed $74 \%$ of the respondents reported they don't have adequate access to water while $44.1 \%$ stated household access to water is poor (Table 3). While $28 \%$ attributed water scarcity to seasonal factor, $38.2 \%$ attributed it to high population. Regular water supply sources were found to be well at $81.5 \%$ and $57.9 \%$ indicated usual dryness of water sources. Duration of dryness was found to be mainly as short as two days at $48.8 \%$ and long as two months at $29.1 \%$.

\section{Survival Strategies During Scarcity and Quality of Available Water}

Alternatives were sought after in order to survive their water challenges. The study showed that during dryness, $53.5 \%$ of the respondents' trekked long distances to assess potable water while $28.7 \%$ stated they got water from a nearby compound (Table 4). The study found out that $72 \%$ of the water in this area isn't suitable for drinking and $54.7 \%$ rely on buying sachet water while $45.3 \%$ rely on buying borehole water for drinking. $63.4 \%$ rely on using aluminum sulphate for water treatment while $42.2 \%$ stated their water isn't usually treated.

\section{Environmental Challenges Contaminating of Water Sources and Intervention Efforts}

The highest source of contamination of the water sources was found out to be poor waste disposal practices with the usual contaminant being human waste (Table 5). Majority of the respondents reported nothing has been done by the community leaders and the government to curb this.

\section{Quantity of Water Needed and Quantity Obtainable}

Only $70 \%$ of water demand is what is met as shown in average household water demand and average quantity obtainable (Table 6). 
Table 1. Socio-demographic distribution of respondent

\begin{tabular}{|c|c|c|}
\hline \multicolumn{3}{|c|}{ Gender of Respondents } \\
\hline & Frequency & Percent \\
\hline Male & 122 & 48 \\
\hline Female & 132 & 52 \\
\hline Total & 254 & 100 \\
\hline \multicolumn{3}{|c|}{ Marital Status of Respondents } \\
\hline & Frequency & Percent \\
\hline Single & 136 & 53.5 \\
\hline Married & 92 & 36.2 \\
\hline Divorced & 26 & 10.2 \\
\hline Total & 254 & 100 \\
\hline \multicolumn{3}{|c|}{ Level of Education } \\
\hline & Frequency & Percent \\
\hline Primary Education & 41 & 16.1 \\
\hline Secondary Education & 122 & 48 \\
\hline Tertiary Education & 91 & 35.8 \\
\hline Total & 254 & 100 \\
\hline \multicolumn{3}{|c|}{ Employment Status } \\
\hline & Frequency & Percent \\
\hline Yes & 229 & 90.2 \\
\hline No & 25 & 9.8 \\
\hline Total & 254 & 100 \\
\hline \multicolumn{3}{|c|}{ House Types } \\
\hline & Frequency & Percent \\
\hline Single room & 116 & 45.7 \\
\hline Room and parlour & 138 & 54.3 \\
\hline Total & 254 & 100 \\
\hline \multicolumn{3}{|c|}{ House Ownership } \\
\hline & Frequency & Percent \\
\hline Self & 26 & 10.2 \\
\hline Rented & 228 & 89.8 \\
\hline Total & 254 & 100 \\
\hline
\end{tabular}

Source: Field survey, 2018

Further analysis of the results was carried out by testing two different hypotheses to know the relationship between a number of variables. Taking $1 \%$ probability level, we can see that the Pearson correlation coefficient, $r$, is 0.948 , and that is statistically significant $(\mathrm{p}=0.000)$ (Table 7). This implies that there is a significant relationship between household water demand per day and quantity available. 
Table 2. Socio-demographic distribution of respondent

\begin{tabular}{|l|l|l|l|l|}
\hline \multicolumn{1}{|c|}{ Domain } & \multicolumn{1}{c|}{ Minimum } & \multicolumn{1}{c|}{ Maximum } & \multicolumn{1}{c|}{ Mean } & \multicolumn{1}{c|}{ Std. Deviation } \\
\hline Age of Respondent & 20 & 56 & 32.5512 & 10.01675 \\
\hline No of children per household & 2 & 10 & 4.9567 & 2.63342 \\
\hline No of adult per household & 5 & 20 & 8.9921 & 3.92115 \\
\hline Monthly income (USD) & 28 & 140 & 66.437 & 32.70 \\
\hline No of individuals per household & 11 & 30 & 16.2717 & 5.22091 \\
\hline
\end{tabular}

Source: Field survey, 2018

\section{CONCLUSION, FUTURE RESEARCH WORK AND LIMITATION}

\section{Conclusion}

Motivations for this study came from the need to investigate water availability challenges in a low-income urban area of Agbowo. The study assessed the effect of changing climate on water availability, investigated survival strategies during scarcity and quality of available water, enumerated environmental challenges contributing to contamination of water sources and looked at intervention efforts aimed at improving access to water in the area while at the same time comparing the quantity of water needed against quantity obtainable.

Data obtained showed that the respondents are predominantly females at $52 \%$ while $53.5 \%$ of the respondents are single. Majority of the respondent have attained secondary education. The community is dominated by people living in a room and parlour apartment at $53.4 \%$ with $89.8 \%$ being rented. Inadequate access to water was reported by $74 \%$ of the respondents with $44.1 \%$ stating household access to water is poor. $28 \%$ attributed water scarcity to seasonal factor such as lack of rainfall during the dry season while $38.2 \%$ attributed it to overpopulation. Regular water sources were found to be well at $81.5 \%$ and $57.9 \%$ indicated usual dryness of water. Investigation showed that the duration of dryness could be as long as two months at $29.1 \%$. Households having high population density with low earning potential further enumerate the characteristics of low-income communities as most live on less than $\$ 1$ per day coupled with poor job reliability and many moved from one job to another at regular intervals.

About 53.5\% reported trekking long distances to get water while $72 \%$ of the respondent stated the water is not suitable for drinking. About $54.7 \%$ have to rely on sachet water for drinking while $45.3 \%$ rely on buying borehole water. Domestic waste disposal practices were reported to be the highest sources of contamination at $61.4 \%$ followed by human waste at $29.5 \%$. Efforts by community leaders showed no hope as $91.7 \%$ reported nothing has been done so far.

From the findings, it is evident that Agbowo community does not have adequate access to water ( $70 \%$ of the demand is currently met) as many rated their household access to water to be poor. The effect of the seasonality of rainfall on water availability cannot be underestimated even though the availability of rainfall does not prevent water supply challenges as the issue was not only about the quantity of the water but also its quality. Regular water sources found in Agbowo community was well water. This is why the community is prone to periodic water shortages as wells become easily dried and go deeper as rainfall reduces. And during heavy downpours, wastewater from drainages gets washed into well waters thereby affecting the quality of available water leading to the spread of water-borne diseases.

Not being able to meet growing water demand as the population in Agbowo community continues to increase suggests the need for an immediate solution. Making water available will not a record-high success if the water is not of good quality. As effort needs to be made regarding water scarcity, an effort also needs to be made regarding the quality. The study showed the need to address the effect 
Table 3. Assessment of the effect of changing climate water availability

\begin{tabular}{|c|c|c|}
\hline \multicolumn{3}{|c|}{ Adequate Access to Water } \\
\hline Domain & Frequency & Percent \\
\hline Yes & 20 & 7.9 \\
\hline No & 188 & 74 \\
\hline Cannot say & 46 & 18.1 \\
\hline Total & 254 & 100 \\
\hline \multicolumn{3}{|c|}{ Rating of Household Access to Water } \\
\hline Domain & Frequency & Percent \\
\hline Fair & 142 & 55.9 \\
\hline Poor & 112 & 44.1 \\
\hline Total & 254 & 100 \\
\hline \multicolumn{3}{|c|}{ Factors Responsible for Scarcity } \\
\hline Domain & Frequency & Percent \\
\hline Dry season & 71 & 28 \\
\hline high population & 97 & 38.2 \\
\hline never happen & 20 & 7.9 \\
\hline no nearby source & 66 & 25.8 \\
\hline Total & 254 & 100 \\
\hline \multicolumn{3}{|c|}{ Regular Water Supply Sources } \\
\hline Domain & Frequency & Percent \\
\hline Well & 207 & 81.5 \\
\hline Borehole & 47 & 18.5 \\
\hline Total & 254 & 100 \\
\hline \multicolumn{3}{|c|}{ Dryness of Water Sources } \\
\hline Domain & Frequency & Percent \\
\hline Yes & 147 & 57.9 \\
\hline No & 87 & 34.3 \\
\hline Cannot say & 20 & 7.9 \\
\hline Total & 254 & 100 \\
\hline \multicolumn{3}{|c|}{ Duration of Dryness } \\
\hline Domain & Frequency & Percent \\
\hline 2 days & 124 & 48.8 \\
\hline 1 week & 14 & 5.5 \\
\hline A fortnight & 20 & 7.8 \\
\hline 2 month & 74 & 29.1 \\
\hline 3 month & 22 & 8.7 \\
\hline Total & 254 & 100 \\
\hline
\end{tabular}

Source: Field survey, 2018 
Table 4. Survival strategies and quality of available water

\begin{tabular}{|c|c|c|}
\hline \multicolumn{3}{|c|}{ Alternate Option During Dryness } \\
\hline Domain & Frequency & Percent \\
\hline Trek long distances & 136 & 53.5 \\
\hline Beg for water & 9 & 3.5 \\
\hline Buy borehole water & 8 & 3.1 \\
\hline Drill the well again & 14 & 5.5 \\
\hline Fetch from a nearby compound & 73 & 28.7 \\
\hline Take tap water from church & 14 & 5.5 \\
\hline Total & 254 & 100 \\
\hline \multicolumn{3}{|c|}{ Suitability for Drinking } \\
\hline Domain & Frequency & Percent \\
\hline Yes & 71 & 28 \\
\hline No & 183 & 72 \\
\hline Total & 254 & 100 \\
\hline \multicolumn{3}{|c|}{ Alternate Options for Getting Drinkable Water } \\
\hline Domain & Frequency & Percent \\
\hline Buy Sachet water & 139 & 54.7 \\
\hline Buy Borehole water & 115 & 45.3 \\
\hline Total & 254 & 100 \\
\hline \multicolumn{3}{|c|}{ Water Treatment Methods } \\
\hline Domain & Frequency & Percent \\
\hline Boiling & 93 & 36.6 \\
\hline Using alum & 161 & 63.4 \\
\hline Total & 254 & 100 \\
\hline \multicolumn{3}{|c|}{ Frequency of Treatment } \\
\hline Domain & Frequency & Percent \\
\hline Not treated & 107 & 42.2 \\
\hline Once in a month & 46 & 18.1 \\
\hline Twice a month & 26 & 10.2 \\
\hline Once in 2 month & 50 & 19.2 \\
\hline Twice a year & 25 & 9.8 \\
\hline Total & 254 & 100 \\
\hline
\end{tabular}

Source: Field survey, 2018

of domestic waste and human waste on contamination which are serious environmental challenges affecting Agbowo Community.

According to WWAP (2019), water reuse can help alleviate water scarcity. For example, nonportable water produced from reclaimed water can be used for car washing, landscape irrigation, industrial processing, and toilet flushing. This study is of the opinion that water reuse should be encouraged in the area. Similarly, unplanned and unrestricted expansion of urban centres must 
Table 5. Sources of contamination and intervention efforts aimed at improving water access

\begin{tabular}{|c|c|c|}
\hline \multicolumn{3}{|c|}{ Source of Contamination } \\
\hline Domain & Frequency & Percent \\
\hline waste disposal & 156 & 61.4 \\
\hline nearby drainage & 46 & 18.1 \\
\hline human waste & 52 & 20.5 \\
\hline Total & 254 & 100 \\
\hline \multicolumn{3}{|c|}{ Effort of Community Leaders } \\
\hline Domain & Frequency & Percent \\
\hline Yes & 21 & 8.3 \\
\hline No & 233 & 91.7 \\
\hline Total & 254 & 100 \\
\hline \multicolumn{3}{|c|}{ Effort by Government } \\
\hline Domain & Frequency & Percent \\
\hline No & 254 & 100 \\
\hline
\end{tabular}

Source: Field survey, 2018

Table 6. Household demand and quantity obtainable

\begin{tabular}{|l|l|l|l|l|}
\hline \multicolumn{1}{|c|}{ Domain } & \multicolumn{1}{|c|}{$\begin{array}{c}\text { Minimum } \\
\text { (Litres) }\end{array}$} & \multicolumn{1}{|c|}{$\begin{array}{c}\text { Maximum } \\
\text { (Litres) }\end{array}$} & $\begin{array}{c}\text { Mean } \\
\text { (Litres) }\end{array}$ & \multicolumn{1}{c|}{$\begin{array}{c}\text { Std. Deviation } \\
\text { (Litres) }\end{array}$} \\
\hline Household demand per day & 80 & 220 & 152.24 & 42.95 \\
\hline Quantity obtainable per day & 50 & 160 & 105.75 & 33.94 \\
\hline
\end{tabular}

Source: Field survey, 2018

Table 7. Showing the Pearson correlation coefficient, $r$, between household water demand per day and quantity available

\begin{tabular}{|l|l|l|l|}
\hline \multicolumn{2}{|c|}{ Correlations } \\
\hline \multirow{3}{*}{ Household water demand per day } & Pearson Correlation & $\begin{array}{c}\text { Household Water } \\
\text { Demand per Day }\end{array}$ & $\begin{array}{c}\text { Quantity Obtainable } \\
\text { per Day }\end{array}$ \\
\cline { 2 - 4 } & Sig. (2-tailed) & 1 & $.948^{* *}$ \\
\cline { 2 - 4 } & $\mathrm{N}$ & 254 & .000 \\
\hline \multirow{2}{*}{$* *$ Correlation is significant at the 0.01 level (2-tailed). } & & 254 \\
\hline
\end{tabular}

Source: Field survey, 2018

be curtailed. Leaks in the water distribution systems as well as in homes and businesses must be minimized. Water conservation needs to be promoted among all water users. According to WHO \& UN Water (2018), improved water sources include piped household connections, public taps or standpipes, boreholes, tube wells, protected dug wells, protected springs, rainwater, tanker trucks and bottled water, while unimproved sources include unprotected dug wells and unprotected springs. The finding of this study shows that Agbowo community is filled with unimproved water sources. In order 
to improve the current figures and in a sustainable manner provide universal clean and affordable water, efficient water policies are required.

To address scarcity, the study is of the opinion that water improving infrastructure must be a priority, as water conservation and efficiency are key components of sustainable water management. Solar desalination and smart irrigation systems are great examples of clean technology for water efficiency and control. Rainwater harvesting and recycled wastewaters also allow reducing scarcity and easing pressures on groundwater and other natural water bodies. Groundwater recharge, that allows water moving from surface water to groundwater, is a well-known process to prevent water scarcity. Without proper sanitation, the water becomes full of diseases and unsafe to drink. That is why addressing pollution, measuring and monitoring water quality is essential. Besides, improving the sewage systems in specific areas of the community is another way to prevent water scarcity from becoming any worse. Head of households can also explore the process of collective action and community group meetings where water needs, future target and present state are discussed.

\section{Future Research Work}

It is evident research on water availability challenges is growing every day, there are many pressing areas that require additional study in order to enable researchers, policymakers, and others to fully adopt a sustainable water supply system and scheme. Areas such as investigation of a microbial contaminant in soil, physical-chemical analysis of soil samples close to water bodies, the impact of the climate on water, behaviour of water user and system modelling of water supply policies and intervention efforts need to be accorded attention. Also, climate change should not divert attention from fundamental food security and development aims and objectives, and achievement of the Sustainable Development Goals. Also, the risk associated with water shortages should be mainstreamed into other parts of sustainable living and other cases to confirm or contradict the results of this study should be carried out.

\section{Limitations of the Study}

The study on Water Availability Challenges in Low-Income Area of Agbowo Community, Ibadan, Nigeria was conducted with substantial cooperation of the respondent owing to the effect it had on them. In some cases, observation method was used for verification of given information. Their responses are subject to error due to poor understanding, inadequate knowledge and inadequate ability to recall some issues as many do not keep the record. Also, the unavailability of data regarding the recent policy plans, targets and sector evaluation in Oyo State is a limitation of the thesis. The results of the study cannot be generalized beyond developing countries, and all generalization should be confirmed with careful context-specific information.

\section{ACKNOWLEDGMENT}

Our utmost appreciation goes to God Almighty for His goodness to us. Special thanks to Africa Water Association (AfWA) for funding this study and to Centre for Sustainable Development (CESDEV) and the University of Ibadan for all the supports they offered. The authors appreciate the review done by Omotola Ogundipe and Toyib Aremu.

\section{FUNDING AGENCY}

Open Access Funding for this article has been provided by IGI Global. 


\section{REFERENCES}

Adah, P.D., \& Abok, G. (2013). Challenges of urban water management in Nigeria: The Way Forward. Journal of Environmental Sciences and Resource Management, 5(1), 7-8.

Africa Development Bank Group (AFDB). (2013). Africa's economic development is held back by episodes of extreme drought and flooding that hydro-climatic variability will only get worse with climate change. Retrieved from http://infrastructureafrica

Ajijah, A. (2013). Nigeria: 363 people killed in 2012 flood, 2.3 Million Others Displaced -NEMA. Premium Times.

Akpomunie, O. B. (2010). Self-help as a strategy for rural development in Nigeria: A bottom-up Approach. Journal of Alternative Perspectives in the Social Sciences., 2(1), 88-111.

BBC News. (2012). Niger floods cause widespread devastation. Retrieved from http:// www.bbc.co.uk/news/ world-africa-19384377

Bradley, J., Holmes, B., \& Thomas, S. (2007). Water quality snapshot 2001-2002: Historic baseline data for the Mount Lofty Ranges Watershed. Academic Press.

Clark, J., \& Carney, D. (2008). Sustainable Livelihoods Approaches: What Have We Learnt? A Seminar Report, ESRC.

DfID. (2001). Sustainable Livelihoods Guidance Sheet. Department of International Development (DfID).

Doe, W. H. (2007). Assessing the challenges of water supply in urban Ghana: A case of North Teshie (MSc. Thesis). Royal Institute of Technology.

Elimelech, M. (2006). The global challenge for adequate and safe water. Journal of Water Supply: Research \& Technology - Aqua, 55(1), 3-8. doi:10.2166/aqua.2005.064

Emergency Events Database (EM-DAT). (2013). International Disaster Data Base. Center For Research on the Epidemiology of Disasters- CRED. Retrieved from http://www.emdat.be/result-disasterprofiles?disgroup $=$ natural \&dis_type $=$ Drought $\&$ period $=2012 \$ 2012$

Intergovernmental Panel on Climate Change (IPCC). (2014). Climate change synthesis report 2014. Retrieved from https://www.ipcc.ch/pdf/assessment-report/ar5/syr/AR5_SYR_FINAL_All_Topics.pdf

Kelay, T., Chenoweth, J., \& Fife-Schwa, C. (2006). Trend report on consumer trends, cross-cutting issues across Europe. TECHNEAU.

Ludi, E. (2009). Climate change, water and food security. Oversees Development Institute.

Majuru, B., Michael-Mokoena, M., Jagals, P., \& Hunter, P. R. (2011). Health impact of small-community water supply reliability. International Journal of Hygiene and Environmental Health, 214(2), 162-166. doi:10.1016/j. ijheh.2010.10.005

Mediel, H., \& Tirimboi, A. (2011). Assessment of Harare water service delivery. Journal of Sustainable Development in Africa, 13(4), 12-15.

Müller, C., Cramer, W., Hare, W. L., \& Lotze-Campen, H. (2011). Climate Change Risks for African Agriculture. Proceedings of the National Academy of Sciences of the United States of America, 108(11), 4313-4315. doi:10.1073/pnas.1015078108

Murinda, S. (2011). Comparative assessment of performance of urban water supply systems in Small towns in Zimbabwe (MSc. Thesis). University of Zimbabwe.

Murray, J., \& Ferguson, M. (2007). Women in transition out of poverty: An asset-based approach to building sustainable livelihoods. Women and Economic Development Consortium. Retrieved from: http://www.cdnwomen.org

Obeta Michael Chukwuma. (2016). Patterns and problems of domestic water supply to rural communities in Enugu State, Nigeria. Hydrology and Water Resources Unit, Department of Geography, University of Nigeria, Nsukka, Enugu State, Nigeria. 
Olaleye, Y. L. (2010). The contributions of the doctrine of citizens' participation in organization and implementation of community development project. European Journal of Scientific Research, 2(2), 12-13.

Olayide, Tetteh, Porter, \& Popoola. (2016). Review and analysis of vulnerability to rainfall variability and policy responses to agricultural water supply in Nigeria. Journal of Food, Agriculture \& Environment, 14(2), 152-155.

Olayide, O. E., \& Ikpi, A. E. (2013). Monitoring Impact Analysis of Microfinance Institutions On Rural Households Wellbeing In Oyo State: A Case Study Of Ifad/Rufin Supported Project. Paper presented at the First International Conference of International Association of Research Scholars and Fellows (IARSAF), International Institute of Tropical Agriculture (IITA), Ibadan, Nigeria.

Segrave, A. J. (2007). Report on trends in the Netherlands. TECHNEAU.

Stone, T. (2009). Water supply: Thinking strategically. IMIESA.

The Sphere Project. (2011). Minimum Standards in Water Supply, Sanitation and Hygiene Promotion. Humanitarian Charter and Minimum Standards in Humanitarian Response.

Toyobo, A. E., \& Tanimowo, N. B. (2011). Evaluation of rural water supply schemes in selected communities in Oke-Ogun Area, Oyo State, Nigeria. Global Journal of Science Frontier Research, 11(9), 8-10.

UNESCO. (2013). Water Cooperation 2013; Facts and figures. Retrieved from http://www.unwater.org/watercooperation-2013/water-cooperation/facts-and-figures/en/

UNICEF. (2015). A better life for all. Retrieved From: https://www.unicef.org/southafrica/SAF_overview_country.pdf

UNICEF/ WHO. (2013). Meeting the MDG drinking water and sanitation target - A mid-term assessment of progress. United Nations Children's Fund and World Health Organisation.

United Nations. (2010). Water for Life Decade 2005-2015: The Human Right to Water and Sanitation-Milestone. Retrieved from https://www.un.org/waterforlifedecade/pdf/human_right_to_water_and_sanitation_milestones.pdf

Van Vuuren, L. (2009). The State of Water in South Africa - Are we heading for a Crisis? The Water Wheel, 31-33.

Vidal, J. (2016). Across Africa: The Worst Food Crisis Since 1985 Looms for 50 Million. The Guardian. Retrieved from https://www.theguardian.com/global-development/2016/may/22/africa-worst-famine-since1985-looms-for-50-million

WASH. (2012). Access to Water Sanitation and Hygiene (WASH). Retrieved from http://nigeria.usaid.gov

Water, U. N. (2018). The United Nations world water development report 2018: nature-based solutions for water. Retrieved from https://unesdoc.unesco.org/ark:/48223/pf0000261424

WWAP (UNESCO World Water Assessment Programme). (2019). The United Nations World Water Development Report 2019: Leaving No One Behind. UNESCO.

WWAP (United Nations World Water Assessment Programme). (2015). The United Nations World Water Development Report 2015: Water for a Sustainable World. UNESCO. 
Tosin Gbadegesin is a Sustainable Development Practitioner with competency in Environmental, Economic and Energy Sustainability. He has over three years' research experience working on several development issues such as climate change, energy, agriculture in Africa. He has been a facilitator/paper presenter at several international conferences such as Africa Youth Conference on Climate Change (AFRIYOCC), Symposium for Climate Change and Adaptation in Africa, International Conference on Business and Human Rights in Africa, Development Studies Association conference, Dublin and many more. His education, research experience, and work have earned him leadership position at Barack Obama's Young Africa Leaders Initiative (YALI) RLC Accra, Ghana, and many other notable awards including Outstanding Research Contribution Award from Young African Leaders Journal of Development, Addis-Ababa, Ethiopia. He holds a Master's degree in Sustainable Development Practice from the University of Ibadan, Nigeria. At present, he works in Israel as Blum Global Fellow with Jerusalem Institute for Policy Research and Gigawatt Global. His work is on studying climate change scenarios, environmental and social risk assessments, and energy efficiency of energy intervention projects in Africa.

Olawale Emmanuel Olayide earned a PhD in Agricultural Economics from University of Ibadan, Nigeria and had his Post-doctoral Research Fellowship at the Kwame Nkrumah University of Science and Technology, Kumasi, Ghana. He works at the University of Ibadan Centre for Sustainable Development, His area of research, teaching and consultancy including Agriculture, Climate Change and Sustainability (Social, Economic \& Environmental). He previously served as Research Fellow with the International Institute of Tropical Agriculture (IITA-Ibadan), and as Consultant to the International Food Policy Research Institute (IFPRI), Washington, USA. He is well-published in international peer-reviewed journals. He is also on the Editorial Board of professional organisations and international journals including the International Sustainable Development Research Society (http://isdrs.org/about-isdrs/board/) and Business Strategy and Development journal (https://onlinelibrary.wiley.com/journal/10.1002/(ISSN)2572-3170/ homepage/EditorialBoard.html). 